\title{
Effects of zinc and allopurinol in ameliorating oxidative stress in lead-exposed workers
}

\author{
Dawser Khalil Ismaiel \\ Department of pharmacology and toxicology, \\ College of Pharmacy, university of Baghdad
}

Received: $11 / \mathrm{V} / \mathrm{r} \ldots \varepsilon$; Accepted: $1 / 1 \mathrm{r} / \mathrm{r} \ldots \varepsilon$

\begin{abstract}
Background: Oxidative stress has been recently implicated in the pathogenesis of acute and chronic exposure to lead. Consequently, the potential role of using antioxidants of various types to provide protective effects became a major task in this respect.

Objective: This study was designed to explore the potential antioxidant effects of zinc and allopurinol in ameliorating the oxidation stress induced due to chronic exposure to lead.

Methods: Twenty-four male workers, chronically exposed to lead, were enrolled in the study and treated with a single daily dose of $\cdots \cdot \mathrm{mg}$ zinc sulfate and $\cdots \mathrm{mg}$ allopurinol for $Y$ months. Erythrocyte and plasma MDA, GSH; blood lead, plasma copper and zinc level were measured each month during treatment and one month later after termination of treatment. Only eighteen workers completed the study.

Results: During treatment, zinc and allopurinol significantly reduced excessive MDA production and elevated GSH level in association with decreasing blood lead level and improving the picture of the essential trace elements, copper and zinc in the plasma which were previously altered as a result of lead exposure.

Conclusion: the use of antioxidants like zinc and allopurinol successfully eliminated the oxidative consequences of lead exposure, and the treatment should be continuously maintained as long as there is exposure to lead.
\end{abstract}

Key words: Lead toxicity, oxidative stress, zinc, allopurinol, trace elements.

الخلاصــة

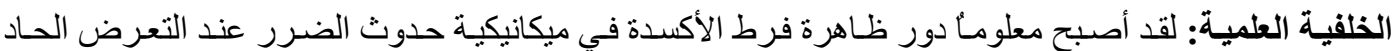
و المزمن للرصاص وتبعأ لذلك برزت إمكانيـة استخدام مضـادات الأكسدة لأغر اض الوقايـة والعلاج في مثل هذه

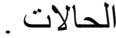

الهـف: تم تصميم هذه الدر اسة لإظهار فعالية كل من الخارصين و الالوبيورينول في الحد من ظـاهرة فرط الإجهاد

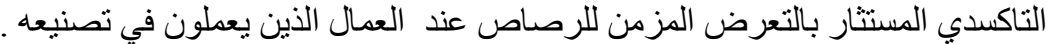

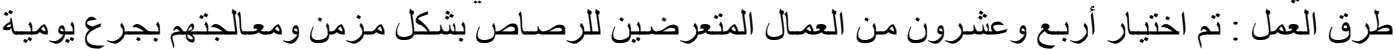

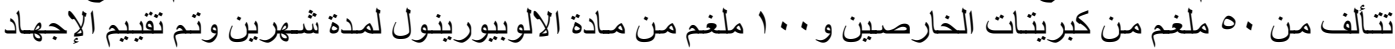

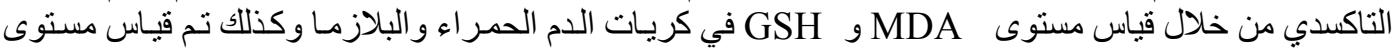

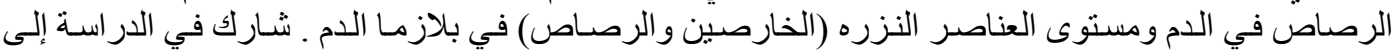

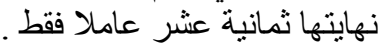

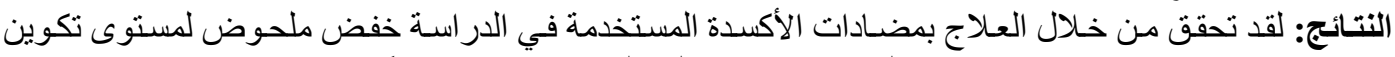

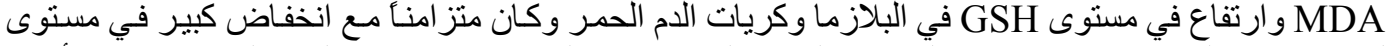

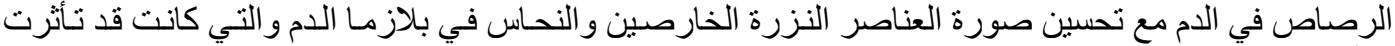

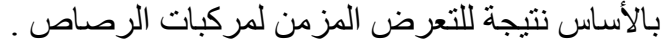

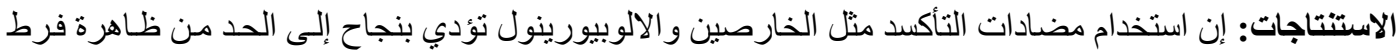

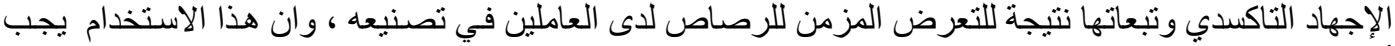

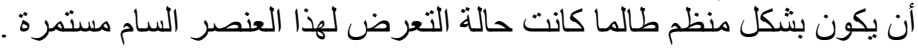




\section{Introduction}

$\mathrm{L}$

ead has no pro-oxidant catalytic activity with respect to peroxidation $^{(')}$ but recently, it was demonstrated that marked enhancement in malondialdehyde (MDA) production was observed as a result of incubation of lead with polyunsaturated fatty $\operatorname{acids}^{\left({ }^{(}\right)}$. This finding was proved in vivo by other investigators, who have pointed to either lipid peroxidation decreased intrinsic antioxidant defenses in various tissues of lead-exposed animals ${ }^{(r)}$. Furthermore, direct relationship was observed between the tissue concentrations of lead and the rate of lipid peroxidation in various tissues especially the brain $\left({ }^{\varepsilon}\right)$. Therefore induction of free radicals formation by lead, and subsequent depletion of antioxidant defenses of the cell can result in generalized disruption of the proxidant / antioxidant balance in lead burdened tissues.

Many literatures support that zinc is an antioxidant that hinders free radical reaction $^{(\circ)}$, and exerts protective role to the cells from the damaging effects of oxygen radicals $^{(\urcorner)}$. The acute antioxidant effects of zinc are generally manifested in the presence of demonstrable short term increase in the levels of this metal, and this basically can be conducted through two mechanisms, sulfhydryl stabilization and reduction in the formation of hydroxyl radicals $\left(\mathrm{OH}^{\prime}\right)$ from superoxide anion and hydrogen peroxide $\left(\mathrm{H}_{\curlyvee} \mathrm{O}_{\curlyvee}\right)$ through antagonism of redox-active transition metals like iron and copper $^{\left({ }^{\vee}\right)}$. Another available approach is to prevent free radical generation by the enzyme system xanthine oxidase (XO), by the use of the $\mathrm{XO}$ inhibitor allopurinol ${ }^{(\wedge)}$. This project was designed to evaluate the possible synergetic effect, which may be gained from the use of combination of zinc sulfate and allopurinol when used in the treatment of the toxic consequences of lead exposure especially in lead processing factories.

\section{Subjects and methods}

This study was carried out on $r \leq$ adult male workers with mean age $\left(r \varepsilon_{-} q_{ \pm} \vee . \varepsilon\right)$ years, in the Iraqi smelter plant in Khan Dhary sub district-Baghdad; they were selected on the basis that they were on direct exposure to lead and have been employed for at least I year before this study was carried out. The daily exposure to lead of each worker should be at least 7 $\wedge \mathrm{hrs}$, and the total period of exposure range from $1-r_{0}$ years, only $1 \wedge$ workers completed the study. Additionally twenty healthy subjects were selected to serve as controls. Lead exposed workers received a daily dose of $0 \cdot-\mathrm{mg}$ zinc sulfate in combination formula with $1 \ldots \mathrm{mg}$ Allopurinol for two months.

Venous blood samples $(l \cdot \mathrm{ml})$ were taken by venepuncture from each worker before starting treatment (as baseline sample), after one month and two months during treatment, and one month later after termination of treatment. Blood samples were placed in two heparinized tubes, the first one utilized for lead level analysis, and the second one is used for separation of plasma and erythrocytes fractions for the measurement of other parameters.

Erythrocytes and plasma MDA levels were measured according to the method of Stocks and Dormandy $(19 \times 1)^{(9)}$ as modified by Gilbert et al $(19 \wedge \varepsilon)^{(1 \cdot)}$. Erythrocytes and plasma GSH levels were measured according to the method of Godin and Wohaieb method $(1911)^{(11)}$.

Plasma copper levels were measured by atomic absorption spectrometry according to Taylor and Bryant method $(1911)^{(1 T)}$, and the same technique was utilized for the measurement of plasma zinc levels according to Taylor and Briggs method (1914 $)^{(15)}$ Blood lead levels were measured by atomic absorption spectrometry according to Brown et al $(1919)^{(1)}$, and blood hemoglobin content was assayed according to the method of Drapkin and Austin (19ro) ${ }^{(10)}$.

Statistical analysis of data was performed using Student's t-test and the 
significance level was considered at $\mathrm{p}$ value less than $\cdot .0^{\circ}$. 
Table (1): Effects of treatment with $0 \cdot m g$ zinc sulfate $+1 \cdots \cdot m g$ allopurinol/ day on erythrocytes and plasma MDA and GSH levels in lead-exposed workers.

\begin{tabular}{|c|c|c|c|c|c|}
\hline \multirow[b]{2}{*}{ Subjects Groups } & \multirow[b]{2}{*}{$\mathrm{N}$} & \multicolumn{2}{|c|}{ Malondialdehyde (MDA) } & \multicolumn{2}{|c|}{ Glutathione (GSH) } \\
\hline & & $\begin{array}{l}\text { Erythrocyte } \\
\mu \mathrm{mol} / \mathrm{g} \mathrm{Hb}\end{array}$ & $\begin{array}{c}\text { Plasma } \\
\mu \mathrm{mol} / \mathrm{L}\end{array}$ & $\begin{array}{l}\text { Erythrocyte } \\
\mu \mathrm{mol} / \mathrm{g} \mathrm{Hb}\end{array}$ & $\begin{array}{c}\text { Plasma } \\
\mu \mathrm{mol} / \mathrm{L}\end{array}$ \\
\hline Control & $T^{\prime}$ & $\begin{array}{c}V . \wedge V^{a} \pm \\
\cdot \wedge \mathrm{Ar}\end{array}$ & $\begin{array}{l}\cdot 97^{\mathrm{a}} \pm \\
.10^{\circ}\end{array}$ & $\begin{array}{l}\text { IY.V } V^{\mathrm{a}} \\
\pm \cdot . V_{0}\end{array}$ & $\begin{array}{l}\cdot \wedge r^{\mathrm{a}} \pm \\
\ddots \cdot v^{2}\end{array}$ \\
\hline Before Treatment & 11 & $\begin{array}{c}r r_{.90^{b}} \pm \\
r .11\end{array}$ & $r . .^{b} \pm \cdot . r^{q}$ & 7.)^{b} \pm \cdot . \leqslant 7$ & $\begin{array}{l}\because 1^{\mathrm{b}} \pm \\
\because{ }^{\mathrm{r}}\end{array}$ \\
\hline $\begin{array}{l}\text { After I month } \\
\text { treatment }\end{array}$ & 11 & IY. $.^{\mathrm{c}} \pm 1 . \Sigma$ & $\begin{array}{l}1 . \leqslant Y^{c} \pm \\
\cdot Y Y\end{array}$ & $V . \Lambda^{b} \pm \cdot . T V$ & $\begin{array}{c}\because 0 \leq^{\mathrm{c}} \pm \\
\because .0\end{array}$ \\
\hline $\begin{array}{l}\text { After } r \text { month } \\
\text { treatment }\end{array}$ & 11 & $V \cdot r^{a} \pm \cdot r V$ & $\because v^{\mathrm{a}} \pm \cdot .9$ & $\begin{array}{c}1 \cdot r^{\mathrm{c}} \pm \\
\cdot .97\end{array}$ & $\begin{array}{l}\ddots V \nearrow^{\mathrm{a}} \pm \\
\ddots \cdot \vee v\end{array}$ \\
\hline $\begin{array}{l}\text { Imonth after the end of } \\
\text { treatment }\end{array}$ & 11 & $9 . \xi^{\mathrm{d}} \pm \cdot .9$ & $1 . \mu^{\mathrm{c}} \pm \cdot r$ & $9 . \cdot^{c} \pm \cdot .9 \leq$ & $\cdot v^{\mathrm{a}} \pm \cdot .0$ \\
\hline
\end{tabular}

* Each value represent mean \pm S.D.

* N=Number of subjects.

$*$ Values with non-Identical superscripts $(\mathrm{a}, \mathrm{b}, \mathrm{c}, \mathrm{d})$ are significantly different $(\mathrm{p}<\bullet . \bullet)$.

Table ( $($ ) $)$ : Effects of treatment with $0 \cdot \mathrm{mg}$ zinc sulfate $+1 \cdots \mathrm{mg}$ Allopurinol/ day on Blood Lead levels, Plasma copper and zinc levels in lead-exposed workers.

\begin{tabular}{|c|c|c|c|c|}
\hline Subjects Groups & $\mathrm{N}$ & $\begin{array}{l}\text { Blood Lead } \\
\text { levels } \mu \mathrm{g} / \mathrm{dl}\end{array}$ & $\begin{array}{c}\text { Plasma Copper } \\
\text { levels } \mu \mathrm{g} / \mathrm{dl}\end{array}$ & $\begin{array}{c}\text { Plasma Zinc } \\
\text { levels } \\
\mu \mathrm{g} / \mathrm{dl}\end{array}$ \\
\hline Control & $\bar{Y}$ & $1 r .10^{a} \pm 1.9 r$ & $99 . r^{\mathrm{a}} \pm 1 \cdot . \wedge$ & $9 Y .00^{\mathrm{a}} \pm 1 Y .7$ \\
\hline Before Treatment & $\begin{array}{l}1 \\
1\end{array}$ & $7 \cdot .1^{b} \pm 1.9$ & $\vee \cdot . \wedge 7^{b} \pm r \cdot r$ & $\vee \vee . \wedge \nearrow^{b} \pm \varepsilon . \wedge$ \\
\hline After ' month treatment & $\begin{array}{l}1 \\
1\end{array}$ & or. ${ }^{b} \pm Y . I \varepsilon$ & $V \wedge . \Delta V^{c} \pm r . r$ & A). $\varepsilon \mu^{b} \pm 7.0$ \\
\hline After $r$ month treatment & $\begin{array}{l}1 \\
1\end{array}$ & $\varepsilon \varepsilon . \nu^{c} \pm 9 . \varepsilon$ & $9 \cdot .0 V^{a} \pm 0.7$ & $q r . q^{a} \pm 0 . \wedge$ \\
\hline $\begin{array}{l}\text { Imonth after the end of } \\
\text { treatment }\end{array}$ & $\begin{array}{l}1 \\
1\end{array}$ & $\varepsilon \Lambda . Y q^{c} \pm 1 \cdot .0$ & $\Lambda \Lambda . \Delta V^{a} \pm r . q$ & $\wedge \cdot .0 \gamma^{b} \pm \varepsilon . \varepsilon$ \\
\hline
\end{tabular}

* Each value represent mean \pm S.D.

* $\mathrm{N}=$ Number of subjects.

* Values with non-identical superscripts $(a, b, c)$ are Significantly different $\left(\mathrm{P}<\bullet^{*} \cdot 0\right)$. 


\section{Results}

The results presented in table (1) showed a highly significant elevation in erythrocytes and plasma MDA content in lead-exposed workers ( $\mathrm{0} 0 \%$ and $r$ r $\%$ respectively) compared with controls.

After 1 month of treatment with $0 \cdot-\mathrm{mg}$ zinc sulfate and $1 \cdots \mathrm{mg}$ allopurinol, significant reduction in the MDA content in erythrocytes (00\%) and plasma (0 $0 \%)$ was observed compared to pretreatment levels, but even with these levels, the values were still significantly higher than controls. Further reduction in MDA level in both compartments was observed ( $\mathrm{V} \leqslant \%$ and $\vee \vee \%$ respectively) comparable with pretreatment levels, and found to be comparable to those in control subjects (Table 1). One month after termination of treatment, MDA levels in both compartments started to increase again reaching values which were significantly different with respect to controls $(\uparrow . \%$ and $\Gamma 0 \%$ in both compartments respectively.

Concerning the effects of lead exposure on GSH levels in erythrocytes and plasma of the workers, table ( 1 ) demonstrated severe depletion of GSH in both compartments ( $₹ 9 \%$ and ^ \%\% respectively), which were significantly different compared to controls. After one-month treatment, GSH levels were elevated in plasma only $(\Gamma q . \%)$ compared to pre-treatment value.

After $r$ months of treatment, GSH levels were increased significantly in both compartments, compared with pre-treatment values ( $7 \mathrm{~V} \%$ and $09 . \%$ respectively) and considered to be comparable to controls in plasma while significantly higher than controls in the erythrocytes. One month after terminations of treatment, no significant changes were observed in GSH content in both compartments, compared to the period of $r$ months of treatment.

Chronic exposure of workers to lead resulted in an increase in blood lead levels ( $\mathrm{r}$ v\%) which was highly significant $(\mathrm{P}<\cdot, \cdot)$ ) compared to controls (Table $r)$. Treatment with a daily dose of ${ }^{0} \cdot-\mathrm{mg}$ zinc sulfate and $1 \cdots \mathrm{mg}$ allopurinol resulted in a significant reduction $(\mathrm{P}<\cdot, \cdot 0)$ in blood lead level only after $r$ months of treatment ( $r \% \%)$ compared to pretreatment value. Termination of treatment resulted in a reversible increase in blood lead, but still significantly lower than that of pre-treatment period (Table $r$ ).

Elevated blood lead was associated with significant decrease in both plasma copper and zinc levels ( $r 9 \%$ and $17 \%$ ) compared to controls. Meanwhile, treatment with zinc sulfate and allopurinol resulted in a significant increase in plasma copper level after 1 month ( $11 \%)$ and in plasma zinc after $r$ months ( $(\wedge \%)$ compared to pre-treatment values (Table $r$ ). Termination of treatment resulted in a reversible decrease in plasma zinc only (1r\%) compared to controls, which is previously normalized as a result of treatment, while plasma copper remain unchanged (Table $r$ ).

\section{Discussion}

Generation of highly reactive oxygen species, such as hydroxyl radical $\left(\mathrm{OH}^{\prime}\right)$, hydrogen peroxide $\left(\mathrm{H}_{r} \mathrm{O}_{r}\right)$, superoxide anion $\left(\mathrm{O}_{r^{*}}\right)$ and lipid peroxides after chronic exposure to lead, may result in systemic mobilization and depletion of the intrinsic antioxidant defenses of the cells, which consequently predispose to a state of oxidative stress $(r)$. The condition that the data presented in table ( 1 ) clearly shown in lead exposed workers, manifested by increased erythrocytes and plasma MDA levels, which are compatible with the observations of others $^{(1-1 \wedge)}$; and depletion of GSH in both compartments which other researchers $(19-r \cdot)$ also observe.

The mechanism by which lead causes it's deleterious effects in this respect has yet to be elucidated; however, part of it's effect may be attributed either to direct effects on cell 
membrane structures and functions ${ }^{\left({ }^{\prime}\right)}$, where red blood cell membrane is found to be highly vulnerable to the oxidative damage of lead ${ }^{(\Upsilon r)}$; or to the blocking of the enzyme glutathione reductase which is responsible for reversible recycling of the oxidized form of glutathione (GSSG) into the reduced form (GSH) ${ }^{(\Upsilon)}$, this effect may result in decreased GSH:GSSG ratio that will render cells more susceptible to oxidative damage.

The effects of daily doses of zinc sulfate $(0 \cdot \mathrm{mg})$ and allopurinol $(1 \cdots \mathrm{mg})$ on the oxidative stress parameters (MDA and GSH) presented in table (1), demonstrated a significant reduction in MDA contents and elevation of GSH levels, which are previously impaired as a result of chronic exposure to lead. These effects clearly explain the antioxidant properties of zinc and allopurinol, which are previously reported in other condition ${ }^{(\Upsilon \varepsilon)}$. Zinc has never been shown to interact directly with an oxidant species, but rather prefer to exert it's effect in an indirect manner ${ }^{\left({ }^{\circ}\right)}$, while allopurinol perform this effect through both directly and indirectly blocking xanthine oxidase ${ }^{(\Upsilon \Upsilon)}$.

Chronic exposure to lead resulted in a significant increase in it's blood levels (Table $r$ ), an observation found by others too ${ }^{(\ulcorner\vee, Y \wedge)}$. The toxic effect of lead may be mediated or enhanced by the interactions or deficiencies of nutritionally essential metals like $\mathrm{Zn}$ and $\mathrm{Cu}$. Lead and zinc interaction are not well defined as those well defined between lead and calcium or iron. It has been shown experimentally that lead increases zinc excretion and that zinc deficiency enhances lead absorption ${ }^{(\Upsilon 9)}$, the effect which is found to be reversed as result of treatment with zinc sulfate and allopurinol (Table $r$ ).

Mylorie et al (19人7) ${ }^{(* \cdot)}$ have suggested an indirect inhibitory effect produced by elevated blood lead levels on the activity of erythrocytes $\mathrm{Cu}-\mathrm{Zn}$-SOD in vivo, and found to be due to lead - induced copper deficiency. Inhibition of SOD activity by lead was also observed in an in vitro study; and this effect was attributed to decreased scavenging of reactive oxygen species (ROS) which consequently predispose to oxidative damage ${ }^{(r)}$. The observed improvement zinc and copper plasma levels (Table $r$ ) as a result of treatment with zinc sulfate and allopurinol very well correlates the role of those compounds in the attenuation of the oxidative stress observed in Table '. In conclusion, the lead-induced oxidative stress after chronic exposure can be successfully interfered with antioxidants like zinc and allopurinol especially why they are regularly administered in fixed daily doses.

\section{References}

1. Rice-Evans, C. Iron-mediated oxi-dative stress in erythrocytes In: Blood cell Biochemistry; Harris, J.R. (ed.), Plenum Press, New York, $199 \cdot$, P.P: $\leqslant$ ₹ $q_{-} \leqslant 0 r$.

r. Somashekaraiah, B.; Padmaja, K.and prasad, A.R. Lead induced lipid peroxidation and antioxidant defense components of developing chick embryos. Free Redic. Biol. Med. 199ץ; $\left.1 \%: 1 \cdot v_{-}\right) 1 \leqslant$.

r. Yiin, S.J. and Lin, T.H. Lead-catalyzed peroxidation of essential unsaturated fatty acid. Biol. Trace Elem. Res. 1990; 0.: ^v-9r.

乏. Shafiq, R. S. Lead-induced regional lipid pre occupation in the brain. Toxicol. Lett. 19^乏; r):rTr-trit.

๑. Terany, A.L. and Sorokin, V. redox, Radicals and antioxidants. In: Oxidants, Antioxidants, and free radicals, Baskin, S.I. and salem, It. (ed.), Tylor and Francis, Washington Dc; $199 \mathrm{~V}$; PP: $1-Y$ l.

7. Bray, T.M. and Bettger, W.J. the physiological role of zinc as antioxidant. Free Radic. Biol. Med. 199 ; A: YNI-r91.

$\checkmark$. Saul, R. P. The antioxidant properties of zinc. American Society for Nutritional Sciences. r...; I!: I $\left.\leqslant \leqslant \vee 0_{-}\right) \leqslant 0$ ro. 
^. Butler, R.; Morris, A.D.; Belch, J.J.; Hill, A. and Struthers, A.D. Allopurinol normalizes endothelial dysfunction in type $r$ diabetics with mild hypertension. Hypertension $r \ldots$; ro (r): V $\leqslant$ T_V0).

१. Stocks, J. and Dormandy, T.L. The autoxidation of human red cell lipids induced by hydrogen peroxide. British J. Haemat. $\left.19 \vee 1 ; ~ r .: 90_{-}\right) 11$.

1 . Gilbert, H.S.; Stamp, D.D. and Roth, E.F. A method to correct for errors caused generation

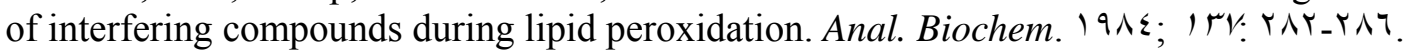

1). Godin, D.V. and Wohaieb, S.A. Nutritional deficiency, starvation and tissue antioxidant status. Free Rad. Biol. Med. 1911; 0: 170_ IV7.

Ir. Taylor, A.J. and Bryant, T.N. Atomic absorption technique for analysis of plasma copper.

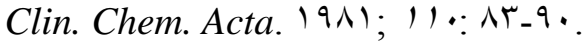

1r. Taylor, A.J. and Briggs, R.Z. Atomic absorption Spectroscopy. Anal. Atom. Spectrosc.

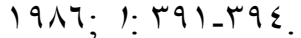

I . Brown, A.A.; Halls, D.J. and Taylor, A.J. Atomic absorption spectroscopy. Anal. Atom. Spectrosc. 1919; $\varepsilon$ : $\leqslant \mathrm{R}-11 \cdot \mathrm{R}$.

10. Drapkin, D.L. and Austin, J.H. Spectrophotometric studies II: Preparations from washed blood cells, Nitric oxide, Haemoglobin and Sulf hemoglobin. J. Biol. Chem. 1940; 11 19:01-10. 